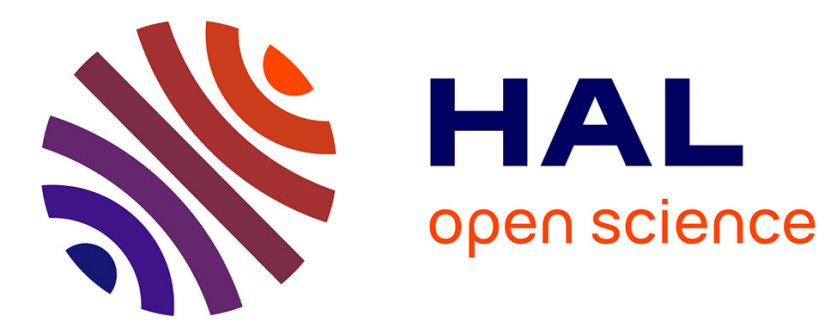

\title{
Misleading mathematical legitimacy and critical passivity: Discussing the irreversible expansion of an ideal gas with beginning teachers
}

\author{
Laurence Viennot
}

\section{- To cite this version:}

Laurence Viennot. Misleading mathematical legitimacy and critical passivity: Discussing the irreversible expansion of an ideal gas with beginning teachers. European Journal of Physics, 2019, 10.1088/1361-6404/ab1d8b . hal-02115881

\section{HAL Id: hal-02115881 \\ https://hal.science/hal-02115881}

Submitted on 30 Apr 2019

HAL is a multi-disciplinary open access archive for the deposit and dissemination of scientific research documents, whether they are published or not. The documents may come from teaching and research institutions in France or abroad, or from public or private research centers.
L'archive ouverte pluridisciplinaire HAL, est destinée au dépôt et à la diffusion de documents scientifiques de niveau recherche, publiés ou non, émanant des établissements d'enseignement et de recherche français ou étrangers, des laboratoires publics ou privés. 


\title{
Misleading mathematical legitimacy and critical passivity: Discussing the irreversible expansion of an ideal gas with beginning teachers
}

\author{
Laurence Viennot
}

Université Paris Diderot, UMR 7057 : Matière et Systèmes Complexes

2019, European Journal of Physics https://doi.org/10.1088/1361-6404/ab1d8b

\begin{abstract}
Given the importance of developing critical analysis skills among students and science teachers, this paper specifically examines a possible barrier that beginning teachers may face in this regard.Using three examples, the paper addresses the issue of 'misleading mathematical legitimacy' $(M M L)$, where modelling negates appropriate physical analysis of a given situation while calculation and results are accurate. The first two examples refer to cases analysed in previous investigations: the 'isobaric hot air balloon' and use of the 'Young relationship' between surface tensions to determine the contact angle of a solid/liquid interface. As these examples are also teaching rituals, this new study eliminates this possible factor of critical passivity by using an unfamiliar solved exercise in which the non-quasi-static expansion of an ideal gas is treated as if the transformation were quasi-static. To document the difficulties experienced by beginning teachers (BTs) in critiquing this text, two group discussions and eight individual interviews were subjected to detailed analysis. The results confirm that $M M L$ features were central to beginning teachers' difficulties, with some less expected findings regarding elementary thermodynamics. The paper concludes with a discussion of objectives for teacher preparation.
\end{abstract}

\section{Introduction}

As critical thinking is universally advocated as an essential goal of science education, it is important to ask how the capacity for critical analysis can be developed in science students and teachers. One crucial issue concerns the links between conceptual and critical development, and this question is explored here in the context of physics. In a previous series of studies based on in-depth interviews with beginning teachers (BTs), the angle of attack was to examine the links between conceptual and critical development in this population when discussing contestable explanations of various physical topics [1]. We observed three main types of interplay between critical attitude and development of conceptual comprehension in the course of an interview. Two of these intellectual dynamics were associated with prolonged 
critical passivity. The first-delayed critique-arises when a person wishes to know more about the given field before offering the slightest criticism of an explanation related to that field, even where no specialized knowledge is required. It may seem obvious that BTs might feel uncomfortable about criticizing a text before feeling conceptually competent in that topic. However, it has also been observed that some individuals overcome their feelings of incompetence to produce a relevant critique even when they know little about the topic in question (characterized as early critique). It is interesting, then, to further explore why some individuals remain reluctant to activate their critical potential even though they have mastered the requisite conceptual elements.

In addition to delayed critique, a second type of critical passivity was observed; expert anaesthesia occurs when a person who is already an expert in the given field fails to detect a serious inconsistency or insufficiency in an explanation related to that field. This more unexpected case indicates that conceptual comfort alone is not a sufficient condition for critique.

The aim of this paper is to further explore and document these two forms of critical passivity. One of the possible causes for such cases of critical passivity is the fact that a fallacious explanation ends with a correct statement - an effect identified in cognitive psychology as confirmation bias [2]. Another possible cause of critical passivity is the existence of teaching rituals [3], that is contestable teaching practices which are both very common and undiscussed. It should be noted that many teaching practices could be described as teaching ritual. This is the case with the "all-or-nothing" rules commonly taught to account for subtractive synthesis, for example, a black pigment would totally absorb all the light received or a green pigment would totally absorb a red light [4]. Another example is the common explanation of the movement of electrons in a circuit by the presence of charges (only) on the poles of the battery ([5, 6]; other examples can be found, for instance, in [7]). What is relevant for the study described in this paper is that such teaching rituals seem likely to diminish BTs' critical vigilance [3].

That said, another hypothesis emerged from the analysis of two intriguing examples in previous investigations [3-8]. In those cases, the explanation provided both a correct result and accurate calculations, but the modelling process was fallacious. Those examples raised the question of whether a form of misleading mathematical legitimacy $(M M L)$ might contribute to the critical passivity observed in teachers. However, the target explanation in both of those cases was a teaching ritual. To test the $M M L$ hypothesis, a new situation of this type concerning a solved exercise in elementary thermodynamics that is not a teaching ritual was used in a series of group discussions and in-depth interviews with BTs. The goal of this investigation was to explore the extent to which such a case-explanation with accurate calculation, correct result and fallacious modelling - would prove difficult to pinpoint because of the effect of mathematical pseudo-legitimation.

Section 1 elaborates the rationale and research questions. Following an account of the content analysis (section 2), the methodology is described, including the procedure adopted for coding the interviews (section 3). The main results (section 4) are recapitulated and discussed in section 5, and the paper ends with a discussion of the implications for research and teacher education.

\section{Rationale, previous studies and research questions}

As a point of departure, we agree with Redish and Hammer's comment [9]: 
Students must be prepared to contend with ambiguities, to make sound judgments about what to accept and what to question, to reconsider past assumptions and adapt to new discoveries. (p. 630)

In seeking appropriate ways of helping students along this pathway, one question arising is the possible content dependence of critical thinking. Our decision to investigate critical thinking in the context of a particular content area (physics) has regard to the long-standing critical debate. While some researchers [10-13] have argued that critical thinking competencies are cross-cutting and can be applied to many areas, others [14-18] have highlighted the specificity of critical thinking criteria in each of these areas. Several authors have conducted reviews of the (countless) studies published on this topic [19-20]. On this basis, it has been suggested that explicit initiation in the main principles of critical thinking should be combined with the development of critical analysis within a given field [21]. Here as in previous studies [1], a grounding position is the view expressed by Willingham [17]: 'Critical thinking is not a set of skills that can be deployed at any time, in any context' (p. 10).

To further explore the issue, we conducted a series of studies based on in-depth interviews with BTs in relation to a number of contestable explanations. The selected topics were the hot air balloon [22]; radiocarbon dating [23]; how a survival blanket works [24]; molecular interactions and osmosis [25] and capillary rise [8]. The convergent and complementary contributions of these studies enabled us to identify three main types of intellectual dynamics during the interviews: delayed critique, early critique and expert anaesthesia. The first and the third of these intellectual dynamics result in prolonged or permanent critical passivity for seemingly opposite reasons. In the case of delayed critique, the participant wants to know more about the addressed topic before venturing any critique; even though they have sufficient knowledge to do so, their feeling of incompetence seems a major obstacle. In the second case, expert anaesthesia, the BT's critical expression seems to be blocked by an excess of confidence in their own knowledge. Speculatively, it might also be said that experts unconsciously tend to complete or reformulate the presented explanation, or they may confound the fact that they understand the topic with the idea that the explanation is sound. Alternatively, they may be following habit, influenced by a kind of principle of economy that leads them to accept what 'works'.

Two examples from previous research are entirely compatible with these assumptions. In the case of the 'isobaric hot air balloon', the purported explanation suggests that 'the atmospheric pressure' is the same inside and outside the balloon, adding sometimes that this is because the balloon is open. It should be clear that, if the situation were isobaric, the balloon would crash to the ground. It would be also difficult to imagine how the balloon could be inflated. In this case, however, the greatest damage would be done to the law of fluid statics $(\Delta p=-\rho g \Delta h)$, as the constitutive link between lift and pressure gradient would be denied. Where an excuse might be offered in terms of simplification (pressure is approximately constant), an appropriate answer would be that such a simplification 'kills' the phenomenon. The notable passivity observed in physics teachers and textbook writers in regard to this topic [3] identifies it as a prototype of a teaching ritual. However, it is also noteworthy that the invalid hypothesis leads, from correct calculation of Archimedean upthrust, to a no less correct result (at the first order) (Box 1). These elements of (apparent) legitimacy seem likely to contribute to the observed expert anaesthesia. A second related example is the diagram often proposed for calculating the angle of contact between a liquid and a solid in the presence of a gas, in which 'surface tensions' (forces by unit length of contact lines) are represented as three arrows drawn on the 'interface lines' (e.g. [26], 305; [27], 458; [28], 24; [29], 82). The arrows 
are shown as starting from the point where these lines of contact meet. Intriguingly, in the direction parallel to the solid surface (vertical in Figure 1), this diagram resembles a free body diagram at equilibrium. Projecting the relevant vectors in this direction yields the Young relationship, which is a correct expression of the angle of contact for the given coefficients of surface tension. However, as argued by a number of researchers [30-31], this Newtonian treatment is hardly justified, as there is no massive matter on a line. That said, justified or not, this diagram is a very commonly used teaching ritual.

Box 1: A hot air balloon (same result for calculations based on two different hypotheses)

Current exercises using the hot air balloon stipulate that internal and external pressures are the same inside and all around the hot air balloon, with a common 'atmospheric pressure' value $p_{O}$. Based on this inconsistent hypothesis, the expected calculation is as follows. For a hot air balloon of total mass $m_{c}$ (solid parts), given the expression of density $\rho$ in an ideal gas of (mean) molar mass $M, \rho=\frac{M p}{R T}$, and Archimedes' theorem, the Newtonian budget at equilibrium is

$$
m_{c}+\frac{M}{R} \frac{p_{\text {int }}}{T_{\text {int }}} V=\frac{M}{R} \frac{p_{\text {ext }}}{T_{\text {ext }}} V
$$

or, admitting that internal and external pressure are equal to their value at opening $p_{0}$ :

$$
\left[1 / T_{\text {Text }}-1 / T_{\text {int }}\right]=m_{c} R /\left(p_{0} M V\right) \text {. }
$$

However, flotation requires a pressure gradient, which is present throughout any fluid (density $\rho$ ) at equilibrium in a gravity field, where $\Delta p=-\rho g \Delta z$. As internal density is lower than external density, internal pressure is everywhere greater than external pressure (at any altitude other than at the aperture), which explains why the envelope is inflated and why flotation occurs.

A calculation at first order based on pressure gradients $(\Delta p=-\rho g \Delta z$ inside and outside) yields the same relationship. 


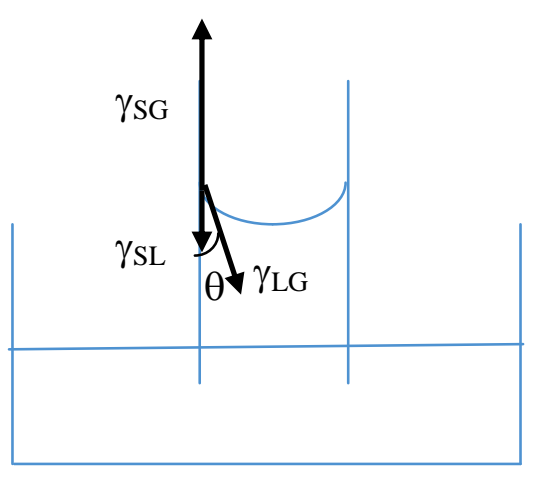

Figure 1. A commonly used diagram to introduce Young's formula $\gamma_{L G} \cos \theta=\gamma_{S G}-\gamma_{S L}$, where $\gamma_{L G}, \gamma_{S G}$ and $\gamma_{S L}$ are surface tension coefficients (forces per unit length) relative to the liquid/gas, solid/gas and solid/liquid interfaces, respectively, and $\theta$ is the contact angle.

These examples suggest that it is worthwhile to further explore the influence of elements of apparent legitimacy (i.e. correct calculation and correct result) on the observed critical passivity among students and experts. To that end, this article examines in particular the role that correct mathematical development and results may play in legitimising an explanation even when the modelling process is inappropriate. The novelty of this approach is that, in contrast to the investigations cited above, the chosen example is not a teaching ritual, and mere habit does not explain any critical passivity.

The study addresses the following research questions.

-RQ1 To what extent do BTs adopt a critical attitude towards text based on inappropriate modelling, despite its apparent mathematical legitimacy $(M M L)$, correct calculation and correct result?

$-R Q 2$ What difficulties do they express in critiquing such a text? Here, we focus on the BT's metacognitive, critical or affective comments, especially those explicating difficulties associated with $M M L$.

As the physical content in question is commonly taught in the first year at university, a further question is also addressed:

$-R Q 3$ To what extent does their critical attitude to this text influence a BT's decision to use it in their teaching without explicit critique? It seems, indeed, that the role of mathematics in physics teaching is a sensitive question, perhaps reflecting priorities informed by the value that BTs confer on physics explanations.

\section{Non-quasi-static expansion of a gas: Content analysis of a solved exercise}

A very common exercise at the start of a course in thermodynamics involves analysing two types of transformation for an ideal gas: $(a)$ a non quasi-static expansion from $V_{A}$ to $V_{B}$ under constant external pressure $p_{\text {ext }}$ and temperature $T_{\text {ext }}$ (pressure passing from $p_{A}$ to $p_{B}$ with $p_{A}>$ $p_{B}$ and $p_{B}=p_{\text {ext }}$ ); and $(b)$ a quasi-static expansion from $V_{A}$ to $V_{B}$ at constant temperature $T_{e x t}$ with $p_{\text {ext }}=p_{\text {int }}=\frac{N R T}{V}$. A variant of the exercise involves the same comparison with processes of compression.

In terms of comprehension of physical processes, such exercises are designed to highlight that, in contrast to $(a)$, the gas in (b) (quasi-static) is considered to be permanently at 
equilibrium. This aligns with the assumption that, in $(b)$, internal pressure and temperature can be defined during the transformation (unlike $a$ ). Consequently, reference to the ideal gas relationship is appropriate during the transformation in $(b)$, but only at the beginning and end of $(a)$. Once this is understood, it is easy to calculate, for instance, the value of the work $W$ done on the gas in both cases.

In both cases, $d W=\int_{A}^{B}-p_{\text {ext }} d V$, where $p_{\text {ext }}$ denotes external pressure and $d V$ denotes an elementary variation in the volume of the gas. In the reversible case, the pressure in the gas, $p_{\text {int }}$, is equal to $p_{\text {ext }}$, with both quantities changing during the transformation. It follows that:

$$
\begin{array}{lll}
\text { Case }(a): & W=\int_{A}^{B}-p_{\text {ext }} d V=p_{B}\left(V_{A^{-}} V_{B}\right) & \left(\text { with } p_{\text {ext }}=C t e=p_{B}\right) \\
\text { Case }(b): & W=\int_{A}^{B}-p_{\text {ext }} d V=\int_{A}^{B}-\frac{N R T}{V} d V=N R T \operatorname{Ln}\left(V_{A^{-}} V_{B}\right) & \left(\text { with } p_{\text {ext }}=p_{\text {int }}=\frac{N R T}{V}\right)
\end{array}
$$

In contrast, the below text (taken from an answer booklet of first-year university exercises: Box 2), refers to the ideal gas relationship for both types of transformation. A priori, this text has two surprising features. First, during a transformation that is not quasi-static, pressure and temperature are not defined, and the ideal gas relationship is not valid; this is denied in the text. Secondly, despite this inappropriate modelling, the result is correct for both transformations.

Box 2. Highly contestable text from a booklet of solved exercises for first-year university students

One mole of an ideal gas is situated in a cylinder, which is closed by a movable piston. It undergoes an expansion from pressure $p_{A}$ to $p_{B}\left(p_{A}>p_{B}\right)$ at constant temperature T. Calculate the work done on the gas in the two following cases:

$a$ - irreversible* expansion, at constant external pressure $\left(p_{\text {ext }}=p_{B}\right)$

$b$ - reversible expansion.

(a) Irreversible case

Work at $T=$ constant for irreversible expansion of one mole of ideal gas: $W_{\text {irrev }}$

$d W=-p d V<0$

$d W_{\text {irrev }}=-p_{\text {ext }} d V=-p_{B} d V$ (because $p_{\text {ext }}=p_{B}$ ).

For our system: $p V=N R T$ and $N=1$ mol. Hence $V=R T / p$ and $d V=-R T d p / p^{2}$

$d W_{\text {irrev }}=-p_{B} d V=R T p_{B} d p / p^{2}$

$W_{\text {irrev }}=\int_{A}^{B} R T p_{B} d p / p^{2}=R T p_{B}\left[\frac{1}{p A}-\frac{1}{p B}\right]=p_{B}\left(V_{A}-V_{B}\right)$

(b) Reversible case (reminder: $p V=N R T$ )

Work at $T=$ constant for reversible expansion of one mole of ideal gas: $W_{\text {rev }}$

$W_{r e v}=\int_{A}^{B}-p d V=\int_{A}^{B}-\frac{N R T}{V} d V=N R T \ln \left(V_{A}-V_{B}\right)$

*The interviewer explains that this "irreversible" transformation is also non-quasistatic.

There is no error in the calculation, and the result is accurate. However, the transformation is modelled using a relationship between volume, temperature and pressure (i.e. the ideal gas law) that holds only for states of equilibrium. Note that we might use various $V(p)$ relationships and still find that the integral $\int_{A}^{B}-p_{B}(d V / d p) d p$ would be equal to $p_{B}\left(V_{A}-V_{B}\right)$, as in the example in Box 3. This box does not justify the use of a relationship of this type, since the whole paper is focused on the fallacy it involves in a non quasistatic case. It just provides 
an illustration of a mechanism by which a fallacious modeling can provide an exact result. Considering that the relationship applies to the initial state and the final state is sufficient for the correct result to be obtained.The important point is that the very idea of an equation of state and defined values of internal temperature and pressure during this transformation are meaningless; in short, the modelling of this situation is clearly defective.

Box 3. Paraphrase* of the solved exercise in Box 2(a), using a fictitious** ideal gas relationship and leading to the same result.

One mole of an ideal gas is situated in a cylinder, which is closed by a movable piston. It undergoes an expansion from pressure $p_{A}$ to $p_{B}\left(p_{A}>p_{B}\right)$ at constant temperature $T$. Calculate the work done on the gas in the two following cases:

$a$ - irreversible expansion, at constant external pressure $\left(p_{\text {ext }}=p_{B}\right)$

$b$ - reversible expansion.

\section{(a) Irreversible case}

Work a $T=$ constant for the irreversible expansion of one mole of ideal gas: $W_{\text {irrev }}$

$d W=-p d V<0$

$d W_{\text {irrev }}=-p_{\text {ext }} d V=-p_{B} d V \quad$ (because $\left.p_{\text {ext }}=p_{B}\right)$.

For our system: $\boldsymbol{p}^{2} V=N R T$ and $N=1$ mol. Hence $V=R T / p^{2}$ and $d V=-2 R T d p / p^{3}$

$d W_{\text {irrev }}=-p_{B} d V=2 R T p_{B} d p / p^{3}$

$W_{\text {irrev }}=\int_{A}^{B} 2 R T p_{B} d p / p^{3}=R T p_{B}\left[\left(\frac{1}{p A}\right)^{2}-\left(\frac{1}{p B}\right)^{2}\right]=p_{B}\left(V_{A^{-}} V_{B}\right)$

\footnotetext{
*In bold: changes relative to the text in Box 2

**Note that this is an inhomogeneous relationship.
}

For present purposes, the interest of this document lies in the following concomitant characteristics: invalid modelling (for case $a$ ); correct calculations and correct result; unusual way of solving this classical problem (for case $a$ ). It seems likely, then, that this case of $M M L$ may constitute a real obstacle for prospective teachers attempting a relevant critical analysis of this solved exercise.

\section{Method}

\section{Pilot study}

Two discussion groups, each comprising three prospective teachers, were organized during a training session in critical analysis. These discussions were transcribed and analysed in light of the research questions. The goal of this pre-analysis was to assess the relevance of these questions and to select some critical arguments that would be expected for this population and context. The participants were first invited to read the text displayed in Box 2, having been informed that the text came from a booklet of solved exercises for first-year university 
students in a preparatory course for medical studies, and that there was no calculation error. These discussions are not reported in detail, contrary to interviews which are described below in the "Individual Interviews" section. Nevertheless, this pilot study was used to guide the main part of this investigation, as explained below. In addition, some excerpts of these discussions will also be cited in the results section to corroborate the interview findings.

A first outcome of the pre-experiment was that no BT found any problem with the calculation:

Well, frankly, I don't know, but for me the calculations are good.

It was also observed that there was no firm rejection of the text during the first fifteen minutes, confirming the interest of further investigation of this topic. Additionally, the analysis showed that participants used two different formulations of what makes this text questionable. Consequently, to guide the interviews and analysis of the transcripts, two critical arguments $(\mathrm{Cl}$ and $\mathrm{C} 2)$ were formulated in relation to the mathematical treatment used to answer the question posed in the text.

$C 1$ For such a mathematical development to be appropriate, the physical quantities $p$ and $T$ should be defined during the expansion of the gas. Therefore, the transformation should be quasi-static (although the non-equivalent term 'irreversible' was used repeatedly during the discussions, as in the text itself, it was clear for all BTs that the transformation was not quasistatic).

$C 2$ The ideal gas law $(p V=N R T)$ is not valid here, even for an ideal gas, as this relationship holds only for states of equilibrium. The transformation should be quasi-static.

Despite their apparent proximity, $C 2$ was not considered identical to $C 1$. Indeed, the preliminary discussions suggested that the fact of being an ideal gas (or not) had a special status in students' minds, which would justify using the $p V=N R T$ relationship whether or not this gas was in thermodynamic equilibrium. For example, commenting on the interviewer's expectations, a participant in a preliminary group discussion gave the following example, without realizing how close he was to appropriate criticism.

- What we're looking for... what we're looking for is just...OK, there are missing steps but we don't care, it's not what interests us. What interests us is that we might not think of something that we admitted as true in there, that could be questioned - for example, it's anything because I don't think that's it, $p V=N R T$; $N$ equals one mole, so $V=R T / p$. Yes, we admit it without any problem, but I mean, it's more like something that we'd be talking about—something that seems completely coherent to us but that in reality isn't necessarily — see what I mean?

It was decided to treat arguments $C 1$ and $C 2$ as distinct when conducting the interviews and when processing the transcripts. These discussions also provided initial confirmation that a case of $M M L$ may be difficult to criticize, as these comments indicate.

- It's true that at first glance, when you see a well-written mathematical formula that arrives at the right result, you have trouble tackling the tool, you know.

- (...) We can criticize but come to exactly the same conclusion (with a correct and an incorrect model)—it's not possible!

\section{Individual Interviews}

The participants in the main investigation were eight voluntary prospective teachers at the very end of their preparation. Interviews were conducted while keeping in mind the critical 
arguments of $C 1$ and $C 2$, which are defined above, and a third argument, $C 3$, which is defined as follows: 'Using the calculation with students, without explicitly critiquing the modeling, should be excluded'. These three critical arguments are recapitulated in Table 1.

The participants were individually interviewed by the author, who had not been involved in their preparation; the mean duration of these interviews was 47 minutes. The BTs were first invited to read the text shown in Box 2, having been informed that it was taken from a booklet of solved exercises for first-year university students in a preparatory course for medical studies, that there was no calculation error and that the results were correct. Given the rich conceptual content and collaborative style of these interviews, it was not possible to plan the course of the discussion in any strict sense.

The interviews always began in a very neutral style in order to collect the participant's first spontaneous comments and to provide them with some more information on the text if necessary.

$\mathrm{X}$ (participant $)_{32 \text { (turn number) }}$ - Uh, we don't contest that the gas is perfect.

Int (Interviewer) - You ask yourself the question?

- Because they say it's at constant temperature, which is not really the case.

- Why isn't that really the case?

Int $_{43}$ - No major remarks? Are you surprised by anything even without criticizing the text?

$\mathrm{E}-\mathrm{Mmmm}$, maybe the fact...I'm trying to remember about irreversible expansions.

- irreversible

- I don't remember having this approach.

- Well, what approach did you have?

- (laughing) I try to remember.

- But that's not how you did it.

- Well, I feel like.

- Are there any particular points that make you think 'I wasn't doing that'?

Progressively, some inputs - comments or questions - were injected by the interviewer, which might take the form of a very general remark (code Gen).

Int $_{57}$. I am very worried about some of the things that are written in this first part. I direct your attention a little more to this, and I tell you again: it is not that there's a bad mathematical manipulation (...) I tell you that I am disturbed for fundamental reasons of physics while telling you the result is correct. Gen

Int $_{67}$ - So what could there be that is questionable, that deserves to be discussed...Maybe nothing? Gen

In cases where the discussion had departed from the relevant points for at least the first 15 minutes, other inputs were more specific. Inputs designed to raise the question of whether pressure can be defined were coded $\boldsymbol{D e} \boldsymbol{f}_{\boldsymbol{p}}$.

Int $_{75}-(\ldots)$ What is pressure? You've been talking to me since the beginning about the inner pressure. $\boldsymbol{D e f} \boldsymbol{f}_{p}$

$\mathrm{S}$ - So? For an irreversible expansion, what is the pressure? Inside? For an irreversible expansion?

- Yes

- Uh

- Do you have any comment about what the internal pressure might be for this irreversible expansion?

- In fact, can we define it, that's the question.

- And this question, you're asking yourself now?

- Yes.

Similarly, inputs intended to raise the question of whether temperature can be defined were coded $\boldsymbol{D e f} \boldsymbol{f}_{\boldsymbol{T}}$ : 
Int $_{95}$ - And you didn't notice that the transformation is said to be isothermal?

S - Yes

- What's temperature? $\boldsymbol{D} \boldsymbol{e} \boldsymbol{f}_{\boldsymbol{T}}$

-In the case of a non quasi-static expansion?

-Yes

-Yeah, well, it's the same thing. We can't define a temperature.

Int $_{67}-(\ldots)$ Does that mean that this transformation is isothermal? $\boldsymbol{D e} \boldsymbol{f}_{\boldsymbol{T}}$

$\mathrm{M}$ - That the system at all times has a well-defined temperature equal to $T$.

- Well defined, I would like to emphasize this - well defined. Can we talk about a well defined temperature?

- Uh (...) that's what's actually weird about irreversible expansion.

Finally, where a question is more or less directly posed or a comment is made about using the relationship $p V=N R T$, but the participant has not yet mentioned this point after 20 minutes, this is coded $\boldsymbol{I} \boldsymbol{G}$.

$\mathrm{S}_{194}-$ Yes, in fact it's useless (to use $p V=N R T$ )... in fact he wanted to do it to compare with the reversible case. -Except that it's illegitimate.

$-\mathrm{Mm}$.

- Can we write $p V=N R T ? \boldsymbol{I} \boldsymbol{G}$

Int $_{129}$ - These are the $d V$ expressions you're showing me. Is there a place where there's already a problem? IG M- Ah, but you can't write the equation of state if you're not at equilibrium.

Int $_{99^{-}}$This function, there, $V(p)$, it comes out of $p V=N R T$.

V-Yes

- It's not posing any questions to you? IG

- From what? Can it come from a relationship like $p V=N R T$ ? $\boldsymbol{I} \boldsymbol{G}$

\section{Coding the interviews}

The two critical arguments $C 1$ and $C 2$ defined on the basis of the pilot study were used to document research question $R Q 1$, which concerns BTs' critical attitude towards this text. Concerning $R Q 2$, the code $\mathbf{m m l}$ designates metacognitive, critical or affective comments about the issue of $M M L$ (when using correct mathematics leads to a correct result although based on an absurd modelling). In such comments, the text under examination was explicitly and spontaneously assigned to this category and was as such considered very misleading and difficult to criticize. Regarding $R Q 3$, transcript processing was focused on the occurrence of argument $C 3$, that is: "It is contestable to use such a demonstration in class without any critical discussion". As in previous studies [1, 4], statements referring to the critical arguments upon which the study is focused - in this case, $C 1, C 2$ or $C 3$ - were coded using three levels of critique, with each code index (1, 2 or 3 ) referring to one of the three arguments. An unambiguous and firm critique was coded $\chi$ ( $\chi$ ritique), an unambiguous and firm acceptance was coded $\alpha$ (acceptation) and a mitigated comment was coded $\mu$ ( $\mu$ itigated comment). These codes and their meaning are recapitulated in Table 1, with examples.

Table 1. Codes used to process the interview transcripts

\begin{tabular}{ll}
\hline Code & \multicolumn{1}{c}{ Critical arguments } \\
\hline $\boldsymbol{C 1}$ & $\begin{array}{l}\text { Critical argument: For such a mathematical development to be appropriate, the physical quantities } p \\
\text { and } T \text { should be defined during the expansion of the gas, which is not the case for a non quasistatic } \\
\text { transformation. }\end{array}$ \\
\hline C2 & $\begin{array}{l}\text { Critical argument: The ideal gas law }(p V=N R T) \text { is not valid here, even for an ideal gas, as this } \\
\text { relationship holds only for states of equilibrium. The transformation should be quasi-static. }\end{array}$ \\
\hline C3 & Critical argument: It is contestable to use such a demonstration in class without any critical discussion. \\
\hline
\end{tabular}




\begin{tabular}{|c|c|c|}
\hline & Levels of critique & Examples \\
\hline$\chi$ & $\begin{array}{ll}\chi_{1} & \text { refers to } C 1 \\
\chi_{2} & \text { refers to } C 2 \\
\chi_{3} & \text { refers to } C 3 \\
\end{array}$ & $\begin{array}{l}X_{42} \text { - So it's a problem because pressure can't be defined } \\
\text { during the expansion. } \chi_{1} \\
M_{130} \text { - Ah but we can't write the equation of state if we're not } \\
\text { at equilibrium. } \chi_{2} \\
S_{240} \text { - I don't teach anything I don't understand. } \chi_{3}\end{array}$ \\
\hline$\alpha$ & $\begin{array}{l}\text { Unambiguous and firm } \\
\text { acceptance } \\
\alpha_{1} \text { refers to } C 1 \\
\alpha_{2} \text { refers to } C 2 \\
\alpha_{3} \text { refers to } C 3\end{array}$ & $\begin{array}{l}\mathrm{X}_{2} \text { - If it's a perfect gas, it's OK. } \boldsymbol{\alpha}_{2} \\
\mathrm{X}_{20} \text { - So far, it makes sense to me. } \boldsymbol{\alpha}_{2} \\
\mathrm{C}_{116} \text { - Oh yeah, that would be a good exercise though, that's } \\
\text { why I'd say...well, I think it's not bad anyway to apply the } \\
\text { classical theory (...) I think, I like it as an exercise. } \boldsymbol{\alpha}_{3}\end{array}$ \\
\hline$\mu$ & $\begin{array}{ll}\mu_{1} & \text { refers to } C 1 \\
\mu_{2} \text { refers to } C 2 \\
\mu_{3} \text { refers to } C 3\end{array}$ & $\begin{array}{l}\mathrm{L}_{112} \text { - (Define temperature?) It depends on the definition you } \\
\text { give of temperature. If it is an isolated system, we can always } \\
\text { get by with a microcanonic definition. } \mu_{1} \\
\mathrm{E}_{166} \text { - We can't use the perfect gas relationship maybe, but } \\
\text { right now, I can't say why we can't use it. } p V=n R T \text {. } \mu_{2} \\
\mathrm{~S}_{192} \text { - (You'd be willing to go so far as to say: I don't want } \\
\text { this text, it's inconsistent.) Uh, that is, what I'd do is look at } \\
\text { books, exercises that deal with irreversible problems, and try } \\
\text { to find one that's as rigorous as possible. And if I don't find } \\
\text { it, I'll do it like that anyway. } \mu_{3}\end{array}$ \\
\hline & Metacognitive comment & Examples \\
\hline$m m l$ & & $\begin{array}{l}\mathrm{L}_{120} \text { - I completely fooled myself. It's devious, it's devious, } \\
\text { it's devious. You find a correct result by a wrong method-a } \\
\text { wrong method but not mathematically wrong-and it's one of } \\
\text { the most perverse things that can happen in physics. } m \boldsymbol{m} \boldsymbol{l} \\
\mathrm{V}_{246} \text { - Well, you can easily get trapped, here and there, by } \\
\text { demonstrations, and then in fact at the mathematical level it } \\
\text { runs smoothly -it works very well, which means you can } \\
\text { easily get trapped. } \boldsymbol{m m l}\end{array}$ \\
\hline
\end{tabular}

Based on the analysis of levels of critical expression, a critical withdrawal is defined as follows: A BT formulates a comment less critical than a previous one, regarding a given argument. In terms of codes, a critical withdrawal means moving, for instance, from $\chi_{2}$ to $\mu_{2}$ or $\alpha_{2}$, or from $\mu_{1}$ to $\alpha_{1}$.

Table 2 maps each BT's intellectual pathway throughout the interview by illustrating the turn number at which each participant expressed a particular code. Given the small sample and indepth analysis, this is a 'case study' type of investigation. However, the number of concerned participants is available for all categories, permitting a very modest but nonetheless quantitative approach that can be used subsequently as part of a cumulative approach to synthesize several studies (as we have previously done in [1], p. 10).

Table 2. Key aspects of individual interviews

\begin{tabular}{llllll}
\hline Participant & Main inputs & Critical & Critical & Explicit & Cricical \\
\hline
\end{tabular}




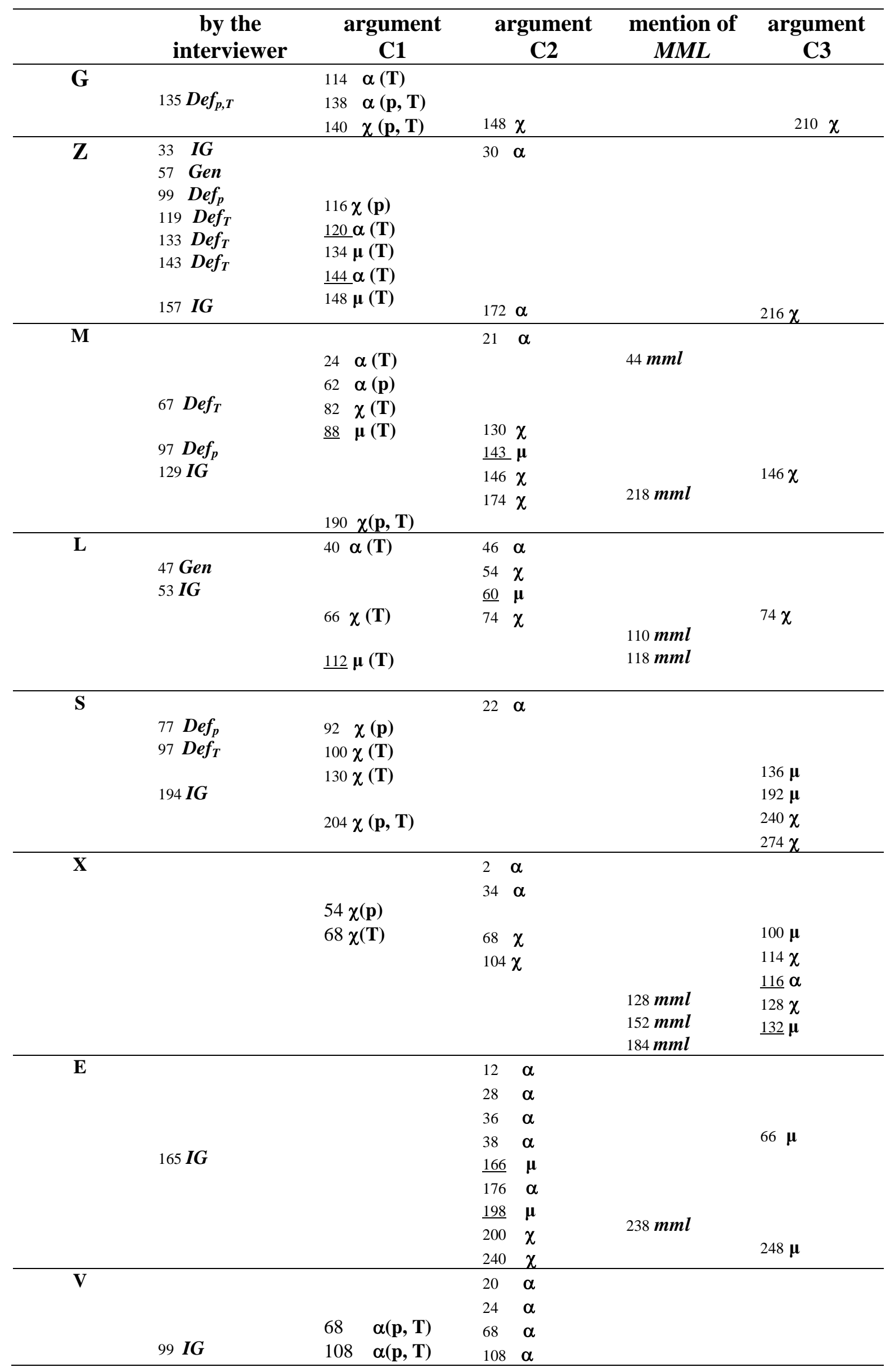




\begin{tabular}{lllllll}
\hline $125 \operatorname{Def}_{p T}$ & 120 & $\alpha(\mathbf{T})$ & 120 & $\alpha$ & & \\
& 146 & $\boldsymbol{\mu}(\mathbf{p})$ & & & $186 \mathrm{mml}$ & $184 \boldsymbol{\mu}$ \\
& & & & & $196 \mathrm{mml}$ & $188 \boldsymbol{\mu}$ \\
& & & & $246 \mathrm{mml}$ & \\
& & & & $250 \chi$ \\
\hline
\end{tabular}

*The numbers are exchange turns. See text for the codes of the interviewer's inputs (col. 2). The levels of critique (codes in Table 1) are shown in col. 3, 4, 6. Concerning Cl, they may be referred to one particular physical quantity ( $\mathrm{T}$ or $\mathrm{p}$ ) or both. An underlined number denotes a critical withdrawal.

\section{Results}

A first finding is that all BTs began their reading with step-by-step checking of the symbols' meanings and the accuracy of the calculations. No BT contested the accuracy of the calculations. With respect to BTs' critical attitude during interviews, the coding of the transcripts summarized in Table 2 sheds light on each of the research questions as follows.

RQ1: To what extent do BTs adopt a critical attitude towards text based on inappropriate modelling, despite its apparent mathematical legitimacy, correct calculation and correct result $(M M L)$ ?

Table 2 (col. 3 and 4) shows the prevalence of $\boldsymbol{\alpha}$ codes (accepting the proposed explanation) during the first part of the interviews. With regard to $C 1$, only $4 \mathrm{BTs}(\mathrm{M}, \mathrm{L}, \mathrm{S}, \mathrm{X})$ expressed a first firm critique during the first 20 minutes; two others $(\mathrm{G}, \mathrm{Z})$ were later, and two others $(\mathrm{E}$, V) made no such attempt. As far as $C 2$ is concerned, only 3 BTs expressed a first firm critique before 26 minutes; two others $(\mathrm{E}, \mathrm{G})$ were later, and the three others $(\mathrm{S}, \mathrm{V}, \mathrm{Z})$ made no such attempt. It is therefore appropriate to speak of delayed critique for most BTs, although to differing degrees for each. Note that mentioning the problem of defining pressure and temperature in case $a$ does not mean that this point is understood, as the following comment demonstrates.

$\mathrm{X}_{58}$ - It's an argument...uh, out of equilibrium, you can't define pressure; it makes sense in my head.

- I confirm that this idea is correct.

- Yeah, but I don't have the arguments yet to say, uh, well, I couldn't explain right away why.

As for the non-equivalence of arguments $C 1$ and $C 2$ detected in the pilot investigation, this was confirmed by several comments. $S$ explained the problems created by the definition and constancy of temperature $T$ while maintaining his adhesion to using the relationship $p V=$ NRT.

$\mathrm{S}_{130}$ - Yes, after all, we do use it (temperature), anyway, yes. (...) Yes, $p V=N R T$. He takes the temperature out of the integral, in fact he treated the system temperature as a constant. If we can't define the temperature of the system, it's a little annoying.

- Yes

- So, it should be said that we consider that we can define a temperature and that it is constant to make the calculation.

It should be noted that the $C 2$ argument seems particularly unobvious to BTs. This critique was expressed very late, that is, by only three participants before 26 minutes $(\mathrm{M}, \mathrm{L}, \mathrm{X})$, two later $(\mathrm{G}, \mathrm{E})$ and three never $(\mathrm{Z}, \mathrm{S}, \mathrm{V})$. There seemed to be a tendency to rely on an ontological legitimacy to justify the use of the law of perfect gas: provided the gas in question actually 'is a perfect gas', whether it is at equilibrium or not, the law is said to hold:

$\mathrm{X}_{2}$ - If it's an ideal gas, it's OK. $\boldsymbol{\alpha}_{2}$

$\mathrm{V}_{24}-p V=N R T$. It's the law of ideal gases, so that's for sure. $\boldsymbol{\alpha}_{2}$ 
$\mathrm{Z}_{30}-p V=n R T$, for me it is mandatory. $\boldsymbol{\alpha}_{2}$

In retrospect, a participant commented on this 'automatism':

$Z_{186}$ - I think the fact that we say it's an ideal gas—-for me, it's automatic, that formula there... (11 turns). For me, it was really automatism, and that surprises me.

Regarding the stability of BTs' critical positions once expressed, eight critical withdrawals were observed ( $C_{1}: \mathrm{Z}, \mathrm{M}, \mathrm{L} ; C_{2}: \mathrm{M}, \mathrm{L}, \mathrm{E}$ ). This relatively moderate degree of instability suggests that, delayed though they may be, critiques aligning with arguments $C 1$ and $C 2$ seemed incontestable to their authors once expressed.

RQ2: What difficulties do they express in critiquing such a text? (In particular, what metacognitive, critique or affective comments do they make regarding the link between a $M M L$ situation and their lack of critical vigilance?)

It is notable (Table 2, col. 5) that, on realising what was problematic about the text, 5 of the 8 interviewees spontaneously referred to the difficulty of critique when a calculation and its results are free of any technical error but rely on inappropriate modelling.

$\mathrm{M}_{44}$ - What happened, I can't see the fault (...) the calculations are correct, and so is the result. It would have been easier for me to solve the exercise before I saw this text. $\mathbf{m m l}$

Int $_{109}$ - You said you would never have found it alone.

$\mathrm{L}_{110}$ - Yes, actually, well, uh maintaining a distance from use of the law of ideal gases-it's not simple, maybe because this law looks like...because this law looks so much like a...I don't know.... state equation; when it is written like that, you get the impression that you are only dealing with quantities that are defined, that describe the state of the gas, and that are defined without any, uh without any problem. I wouldn't have thought that the definition of pressure could be difficult or even impossible. So the idea of undefined quantities when you've blackened entire pages... it's hard, yes, because they seem so natural and so well defined. $\mathbf{m m l}$

$\mathrm{V}_{184}$ - It's true that when I read that I completely skipped the irreversibility of the expansion; the fact that $p V=N R T$ was the perfect alibi....in fact it appeared, we use the relationship after we look at what varies; we follow a path...we have the impression that, we arrive, in fact; with all these calculations, we have the impression that finally, well, that is correct—it is scientific, and if there is something that blocks, it is my faultactually, it gives this impression. $\mathbf{m m l}$

Int $_{195}$-You explain it very well- that's the phenomenon we're trying to analyse; that's what happens when math is right, and on top of that the result is right and the modelling is wrong.

V - And we don't see what's behind it. $\mathbf{m m l}$

A wish to overcome this difficulty was sometimes expressed.

$\mathrm{V}_{250}$ - Well, simply the fact that behind each expression...it is necessary to be able to, to explain - that is to say that I see- I must be able to explain even very simple relationships and simple things with words. In any case, we should not hide behind calculations (...) for me, it is especially important not to be leaning behind (sic) calculations.

One noteworthy comment reconsidered the issue of conceptual priorities in teaching thermodynamics.

$\mathrm{M}_{190}$ - Even if it's the only thing I should retain from my thermodynamics course-[in] a system that is not at equilibrium, we can't define intensive quantities. 
RQ3: To what extent does their critical attitude to this text influence a BT's decision to use it in their teaching without explicit critique?

Apart from four BTs (Z, M, L, G) who were firmly opposed to this use of the text, others (S, E, V) also adopted mitigated positions, even though two (S, E) had previously formulated explicit critiques (Table 2, col. 6). The case of $\mathrm{X}$ is still more indicative, as he changed his mind twice (two critical withdrawals). In approval phases, his attitude to this inconsistent explanation extended beyond mere tolerance:

Int $_{111}$ - You're saying we're not allowed to write that?

$\mathrm{X}_{112}$-Yes. $\chi_{3}$

- You say it's a scandal?

- Ah yes, okay.

- Or else you say "it's not quite complete" or "I don't understand well". What are you saying there?

- Ah yeah, that would be a good exercise though, that's why I'd say "It would be a good exercise"—well, I think it's not bad for applying classical theory. $\alpha_{3}$

-5 turns

- I wouldn't want to defend him [the author] either because he uses hypotheses, uh, he uses laws and hypotheses that are false... But then that opens the door to everything, in fact! If the laws and assumptions are wrong, it's actually not good. (3 turns) - Yes, yes, (if) anyway, the basis of physics is that, before applying a law, you have to look at its validity. And then, the fact is, you apply a law without worrying about its validity. In physics, this is unacceptable. $\chi_{3}$

- 3 turns

$\mathrm{X}_{132}$ - On the other hand, in the sense (...) of making use of laws and a little bit of calculation and reinvesting laws in a related exercise, it is good. $\mu_{3}$

In relation to the pedagogical use of this contestable document without any critique, this excerpt illustrates the extent to which a given participant could sustain conflicting views.

\section{Recapitulation and discussion}

The purpose of this investigation was to shed some light on possible critical passivity among BTs at the end of their formation. Based on previous investigations [1, 3, 8], it seemed possible that explanations based on correct calculations and results but inappropriate modelling - that is, misleading mathematical legitimacy-were especially likely to block any critique. The present study tests that assumption by excluding the possibility of critical passivity caused by ritualistic practice. The explanation in question (a solved exercise about the non-quasi-static expansion of an ideal gas) is not frequent in a teaching context. In the text, pressure and temperature are treated as if they were defined during the transformation and linked by the ideal gas relationship, even though this is not valid for a non-quasi-static transformation. Beginning teachers were invited to offer their opinions about this text, its explanatory value, and its possible use (without critique) in class. The study involved two stages. First, by way of pilot investigation, two groups of three BTs were invited to comment on the text during a training session on critical analysis. The transcripts of the corresponding discussions confirmed the relevance of $R Q 1$ (To what extent do BTs adopt a critical attitude to the text despite its apparent mathematical legitimacy $(M M L)$ based on inappropriate modelling, correct calculation and correct result?) and $R Q 2$ (What difficulties do they express in critiquing such a text?).

In the second stage of the investigation, 8 individual interviews (averaging about 45 minutes in duration) were analysed in relation to the two research questions above and $R Q 3$ (To what extent does their critical attitude to this text influence a BT's decision to use it in their teaching without explicit critique?). This last question was also found to be relevant, as suggesting the use of an explanation in class can be seen to indicate the value ascribed to it. 
Indeed, it seems likely that, having detected a flaw in argument $C 1$ or $C 2$, a BT would not subscribe to using the text in class without explicitely criticising it.

These results suggest that, as in other studies [1], the typical intellectual pathway followed by BTs during the interview is characterised by prolonged critical passivity. Given the participants' relative lack of experience and the unfamiliar topic, it may not be appropriate to refer to these cases as "expert anesthesia". However, it is worth noting that no participant claimed to be unaware that pressure and temperature could not be defined for a non quasistatic transformation. The particular form of their critical passivity was surprising in that they failed to criticise the use of $P V=N R T$ for a non-quasi-static transformation. This was true even of participants who had previously said that pressure and temperature could not be defined in such cases. For several participants, being an ideal gas seemed to unconditionally justify the use of this relationship, at least as a first response. To the author's knowledge, this outcome has not previously been reported in the research literature. On this point as well as the issue of defining intensive physical quantities, the participants' comments provide ample confirmation that accurate mathematical treatment and results may block awareness of defective modelling. It might be argued that discussing a document designed by a university teacher is a priori difficult for BTs. It should be noted in this regard that the participants in this study where not very young students, they were already teaching part time and they did not express any feeling of intimidation. Of course, this does not exclude the possibility of a blockage due to an impression of incompetence, a feeling that was often expressed by participants in other studies [1] and might be explored in more detail, for instance by varying the status of the text under study (text taken from the internet or from another BT). Here, BTs' metacognitive comments at the end of the interview were strongly focused on the undue legitimation of an inappropriate modelling by the mathematical process. It is true that this example constitutes a very particular case of questionable explanation, given the accuracy of the results and the fact that it goes against the very logic of its use, which is to illustrate the impossibility of analysing the intermediate steps in a transformation that is not quasi-static. The acceptance of this anomaly by the participants reflects a significant blockage to critical analysis, and they were aware of this surprising fact at the end of the interviews. On this basis, it is not unreasonable to argue that $M M L$ strongly contributes to inhibit criticism in beginning teachers.

Although the goal of this research was to document certain aspects of BTs' intellectual pathways when confronted with a contestable text rather than to evaluate the teaching environment, it is worth noting that all participants were surprised by what emerged from these interviews. In relation to the particular domain (elementary thermodynamics), one unforeseen finding is that these BTs responded as if they were unaware of the conditions for defining intensive physical quantities (pressure and temperature). Still more striking is their unconditional use of the ideal gas relationship once the gas is declared ideal, regardless of its state. These limited findings suggest that it may be worthwhile to further explore these aspects of students' reasoning in this domain.

\section{Final remarks}

It is common to advocate the development of a critical attitude in our students and, therefore, in their teachers. This injunction is not new, and it seems clear that, in some contexts at least, that goal remains unachieved. In pursuit of that goal, the present study contributes to a deeper understanding of the conceptual, metacognitive, critical or affective aspects in play when science learners and prospective teachers are invited to critique a fallacious text. 
In relation to $M M L$, one question that arises is whether such cases are mere curiosities as extreme cases of misleading situations. This issue remains unresolved and warrants further research. For now, it is worth noting that, however strange it may seem, several of these cases are associated with teaching rituals, and the very existence of these rituals suggests that $M M L$ situations are symptomatic of a non-anecdotal phenomenon. There is as yet no inventory or systematic content analysis of such situations. It may be that these 'curiosities' are the proverbial tip of an iceberg, pointing to a widespread but unacknowledged practice. When a BT proposes to make uncritical use in class of an explanation that runs counter to the conceptual target (in order to 'have the laws used and a little bit of calculation and reinvest the laws in an exercise' as one participant put it), this reflects an inversion of values in physics teaching, implying that a mathematical procedure is more important than a correct physical analysis. In contrast, some teachers rejected this inversion at the end of their interview, acknowledging the need to prioritise physical analysis: 'Even if it's the only thing I should retain from my thermodynamics course-[in] a system that is not at equilibrium, we can't define intensive quantities'. These remarks are not intended to devalue the use of mathematics in physics teaching, which is indispensable and provides invaluable benefits, but to highlight some consensual ideas that are difficult to implement in practice. During problem solving, calculations should not obscure sound physical analysis but should complete it by supplying results that must still be submitted to thorough critical appraisal.

In conclusion, it should be recalled that an individual or a group can be considered as mastering a topic when appropriate explanations can be provided, accompanied by an analysis of their conditions of validity, and when questionable arguments can be discussed and possibly rejected in an appropriate way [32].The results of this study, and others cited above, strongly suggest that criticism makes it possible to understand as much as understanding facilitates criticism: it is essential to highlight more explicitly this essential dimension of teacher education. In particular, using more or less complete and/or satisfactory texts and requesting a critical analysis would place future teachers in a situation of personal search for understanding. In such cases, the role of the participants is explicitly to evaluate various arguments put forward by others, not directly to solve a problem. The obstacles to the free expression of critical judgment observed in the research interviews may be significant, but in the limited context of the research described here, the benefits are no less substantial, both in terms of understanding and metacognitive. In this regard, further research is needed to document these difficulties and benefits as accurately as possible, in order to inform the design and evaluation of appropriate environments for teacher education.

\section{References}

[1] Author and Décamp N 2018a Activation of a critical attitude in prospective teachers: from research investigations to guidelines for teacher education Phys. Rev. Phys. Educ. Res. 14, 010133 https://doi.org/10.1103/PhysRevPhysEducRes.14.010133

[2] Nickerson R S 1998 Confirmation bias: A ubiquitous phenomenon in many guises. Review of General Psychology 2(2) 175.

[3] Author 2006 Teaching rituals and students' intellectual satisfaction Phys. Educ. 41 400408. http://stacks.iop.org/0031-9120/41/400

[4] Chauvet, F. 1996 Teaching colour: design and evaluation of a sequence Eur. J. of Teacher Ed. 19 (2) 119-34

[5] Härtel, H. 1985 The electric circuit as a system In R. Duit, W. Jung \& C. von Rhöneck (Eds.) Aspects of understanding electricity (343-352) Keil: Schmidt \& Klaunig 
[6] Chabay, R., \& Sherwood, B. 2006 Restructuring the introductory electricity and magnetism course American Journal of Physics 74(4), 329-336

[7] Slisko, J. 2006 Errores en los libros de texto de física: ¿cuáles son y por qué persisten tanto tiempo? Sinectica 27 13-23

[8] Author and Décamp N 2018b The transition towards critique: discussing capillary ascension with beginning teachers Eur. J. Phys. 39045704 https://doi.org/10.1088/1361-6404/aab33f

[9] Redish E F and Hammer D 2009 Reinventing college physics for biologists: Explicating an epistemological curriculum Am. J. Phys. 77629

[10] Ennis R H 1996 Critical Thinking (Prentice Hall, New York)

[11] Halpern D F 1998 Teaching critical thinking for transfer across domains Am. Psychol. 53 449

[12] Kuhn D A 1999 Developmental model of critical thinking Educ. Res. 2816

[13] Davies M 2013 Critical thinking and the disciplines reconsidered Higher Educ. Res. Dev. 32529

[14] Barrow R 1991 The generic fallacy Educ. Philosophy Theory 237

[15] McPeck J 1981 Critical Thinking and Education (St Martin's Press, New York, NY).

[16] McPeck, J. 1990 Critical thinking and subject specificity: A reply to Ennis, Educ. Res. 19

[17] Willingham, D. T. 2008 Critical thinking: Why is it so hard to teach?, Arts Educ. Policy Rev. 10921

[18] Bailin, S. and Siegel, H. 2003 Critical thinking, in The Blackwell Guide to the Philosophy of Education, edited by N. Blake, P. Smeyers, R. Smith, and P. Standish (Blackwell, Oxford UK, 2003), pp. 181-193.

[19] Abrami P C , Bernard R M, Borokhovski E, Waddington D I, Wade A and Persson T 2015 Strategies for teaching students to think critically: A meta-analysis Rev. Educ. Res. 85275

[20] Davies M 2013 Critical thinking and the disciplines reconsidered Higher Educ. Res. Dev. 32529.

[21] Tiruneh D T, De Cock M and Elen J 2017 Designing learning environments for critical thinking: Examining effective instructional approaches Int. J. Sci and Math. Educ., DOI: 10.1007/s10763-017-9829-z.

[22 Mathé S and Author 2009 Stressing the coherence of physics: Students journalists' and science mediators' reaction Probl. Educ. 21st Century 11 (11) 104-128.

[23] Décamp N and Author 2015 Co-development of conceptual understanding and critical attitude: Analysing texts on radiocarbon dating Int. J. Sci. Educ. 372038

[24] Author and Décamp N 2016a Co-development of conceptual understanding, and critical attitude: Toward a systemic analysis of the survival blanket Eur. J. Phys. 37015702

[25] Author and Décamp N 2016b Conceptual, and critical development in student teachers: First steps towards an integrated comprehension of osmosis Int. J. Sci. Educ. 382197

[26] Brown R C 1974 The surface tension of liquids Contemp. Phys. 15 301-27

[27] G. Bruhat, Cours de physique générale (mécanique), 5e édition, Paris : Masson et Compagnie, 1955.

[28] de Gennes P G, Brochard-Wyart F and Quéré D. 2005 Gouttes, bulles, perles et ondes

[29] Guyon E, Prost J, Betrencourt C, Boulet eC and Bolochine B 1982 « Attention aux tensions superficielles! », European Journal of Physics 3, 159-168

[30] Berry M V 1971 The molecular mechanism of surface tension Phys. Educ. 679

[31] Marchand A, Weijs J H, Snoeijer J. H. and Andreotti B 2011. Why is surface tension parallel to the interface Am. J. Phys. 79999 
[32] Etkina E and Planinšič G 2015 Defining and developing "critical thinking" through devising and testing multiple explanations of the same phenomenon Phys. Teach. 53 432 